\title{
Temporal changes in milk fatty acid distribution due to feeding different levels of rolled safflower seeds to lactating Holstein cows
}

\author{
Amir Ahmadpour, ${ }^{\star} \dagger$ Hassan Aliarabi, ${ }^{* 1}$ Mohammad Ghelich Khan,‡ Robert A. Patton, $\S$ \\ and Rupert M. Bruckmaier† \\ *Department of Animal Sciences, Bu-Ali Sina University, 65178-33131 Hamadan, I. R. Iran \\ †Veterinary Physiology, Vetsuisse Faculty, University of Bern, 3001 Bern, Switzerland \\ fDepartment of Animal, Dairy and Veterinary Sciences, Utah State University, Logan 84322 \\ $\S N i t t a n y$ Dairy Nutrition Inc., Mifflinburg, PA 17844
}

\begin{abstract}
The objective of this experiment was to follow the time-course changes of the milk fatty acids (FA) and particularly conjugated linoleic acid (CLA), n-3, and n-6 FA in response to feeding whole rolled safflower seed (SS). Eighteen cows were blocked by milk production, days in milk, and parity, and randomly assigned to 1 of 3 diets by replacing whole cottonseed with SS. The control diet contained no SS (SS0), whereas the other diets contained $3 \%$ of dry matter as SS (SS3) or $6 \%$ SS (SS6). The study was conducted for 8 wk. Cows fed SS produced more milk than SS0, with SS3 producing more milk than SS6, but without a change in milk fat yield or milk fat \%. Except for C8:0 FA, changes in milk FA were not observed until the third week of SS feeding. The C8:0 began decreasing during wk 1 of SS feeding and continued to decline to wk 8. Short-chain FA (C6:0 to C11:0) and medium-chain FA (C12:0 to C16:1) concentrations decreased in milk when cows were fed SS, whereas long-chain FA (C18:0 and higher) increased after wk 3. The milk long-chain FA increased from wk 3 until wk 5 and then reached a plateau with little difference between SS3 and SS6, whereas the short-chain FA decreased more in milk from cows fed SS6 than SS3. Total CLA increased slightly less than $5 \times$ in milk from cows fed SS compared with SS0. Over the same time frame, n-3 FA declined and n- 6 FA increased in the milk from cows fed SS, with no difference between SS3 and SS6. This study indicated that SS fed at 3 and $6 \%$ of DM had the potential to increase milk production and the CLA in milk, but with a corresponding increase in n-6 FA.
\end{abstract}

Key words: safflower seed, conjugated linoleic acid, temporal fatty acid change

Received September 24, 2016.

Accepted November 22, 2016.

${ }^{1}$ Corresponding author: h_aliarabi@yahoo.com

\section{INTRODUCTION}

Bioactive fatty acids (FA) in milk can have substantial benefits for human health and include CLA (C18:2 cis-9,trans-11 and C18:2 trans-10,cis-12) and the n-3 FA as well as C18:1 trans-11. The CLA are among the most potent anti-carcinogenic compounds (Parodi, 1999). The n-3 FA have been found to aid in the prevention of heart disease (Harris and von Schacky, 2004) and C18:1 trans-11 may also have health benefits due to their conversion to CLA (Bu et al., 2007). Dairy products are the primary source of CLA in the human diet and provide about $10 \%$ of n- 3 FA and $25 \%$ of n- 6 FA (van Valenberg et al., 2013). This suggests that increasing the CLA and n-3 levels in milk may make it a more preferred food source. However, CLA have been shown to cause milk fat depression (Chouinard et al., 1999; Bauman and Griinari, 2001), and increases in the n-6 to n-3 ratio have caused decreased milk production (Greco et al., 2015) and proinflammatory responses in humans and rodents (Calder, 2012). Studying the timecourse of CLA responses in milk can provide insight into the biological mechanism involved in these changes (Harvatine and Bauman, 2011). However, few studies are available on the time course of CLA changes for cows fed safflower seed.

Safflower is well suited to cultivation in warm desert areas, producing a seed high in oil (Dubois et al., 2007). Also among 80 common oil seeds, safflower seed (SS) has the highest content of linoleic acid, which is considered to have an improved profile of milk FA, specifically C18:1 trans-11, CLA, and n-6 content (Bell et al., 2006; Dschaak et al., 2011; Alizadeh et al., 2012). Hence, SS is a viable candidate as a fat source for dairy cows in these environments. Differences in FA responses may be due to use of different sources, different amounts of SS fed, different processing methods (Bu et al., 2007), or the amount of linoleic and linolenic FA ingested (Lock and Bauman, 2004). The time course of milk FA changes due to feeding SS have not been well studied, 
although Bell et al. (2006) reported milk fat depression started the day of feeding, but CLA levels in milk did not occur until after 4 wk later.

The primary objective of this study was to determine the temporal relationships of milk FA changes due to feeding different SS amounts. Secondary objectives were to determine differences in milk fat yield (MFY) and milk fat \% (MFPct) as well as differences in digestible OM between SS fed at 3 or $6 \%$ of the diet DM as an aid to explain FA changes.

\section{MATERIALS AND METHODS}

\section{Animals and Management}

Animal care and sampling procedures were approved by the Animal Care Committee of Bu-Ali University. For this study 18 lactating cows with a mean $\pm \mathrm{SD}$ of $28.6 \pm 4.1 \mathrm{~kg}$ average daily milk yield, $157 \pm 19$ DIM, $545 \pm 48 \mathrm{~kg}$ of BW, and a BCS of $2.3 \pm 0.3$ ( 5 point scale) were used in a randomized complete block design with repeated measurements of variables. Animals were blocked by parity (either primiparous or multiparous (mean parity of $2.8 \pm 1.4$ ), average daily milk yield, and DIM allowing 6 cows for treatment to be assigned to 1 of 3 dietary treatments: no added SS (SS0); SS included at $3 \%$ of ration DM (SS3); or SS included at 6\% of ration DM (SS6). Sufficient SS (variety IL-111) were obtained from a commercial source to last the whole experimental period ( $8 \mathrm{wk})$. Seeds were rolled through 5-mm mesh of a Wiley's Pulverizer (Ogaw Seiki, Tokyo, Japan) roller mill and were added to a TMR. The nutritional and FA content of the SS is presented in Table 1 , whereas the ingredient and nutritional content of the diet, and FA profiles, are presented in Tables 2 and 3, respectively. Diets were designed to be iso-nitrogenous and nearly iso-energetic, as well as being nutritionally adequate for $550-\mathrm{kg}$ cows producing $32 \mathrm{~kg}$ of milk according to NRC (2001). Cows were housed in individual tie stalls with continuous access to water and allowed access to an outside lot 2 times a day for $1 \mathrm{~h}$ of exercise. The TMR was fed twice daily at 0800 and $1800 \mathrm{~h}$, and cows were milked 3 times daily at 0500, 1300, and 2100 $\mathrm{h}$. Cows were weighed and body scored weekly during the 8 wk of the experiment.

\section{Samples and Analysis}

Feed intake and milk yield were recorded daily, whereas samples of TMR were collected on $\mathrm{d} 2$ and 6 of each week and were stored at $-20^{\circ} \mathrm{C}$ until analyzed for nutrient composition. Dry matter of feeds was determined by drying at $110^{\circ} \mathrm{C}$ until a constant weight was obtained. Following drying, ash content was determined as the residue after $8 \mathrm{~h}$ in a $500^{\circ} \mathrm{C}$ furnace. Feed samples were analyzed for ether extract $(\mathbf{E E})$ as method 920.39 and $\mathrm{CP}($ as $\mathrm{N} \times 6.25)$ method 955.04 (AOAC International, 2002). Fiber, as both NDF and ADF, was determined by the methods of Van Soest et al. (1991). Milk samples were obtained the last 2 $\mathrm{d}$ of each week. The 3 daily milk samples were mixed proportionally and a sub-sample of the mixed milk was taken for each cow per day and preserved using Bronopol tablets (Valio Ltd., Helsinki, Finland), and was analyzed for milk true protein, fat, and lactose using a Milko-Scan model 6 (Foss, Hillerød, Denmark). Milk samples were processed for SCC using a DeLaval cell counter (DeLaval, Tumba, Sweden) according to the manufacturer's protocol. Digestibility of ration nutrients were determined using acid insoluble ash as an indigestible marker using the technique of Van Keulen and Young (1977) and the equations from Zhong et al. (2008).

Rumen samples were taken on d 2 of each week 2.5 $\mathrm{h}$ after morning feeding by means of rumenocentesis as described by Tajik et al. (2011). The $\mathrm{pH}$ of the sample was measured immediately using a mobile AR $50 \mathrm{pH}$ meter (Fisher Scientific GmbH, Hamburg, Germany). Another $10 \mathrm{~mL}$ was preserved with $1 \mathrm{~mL}$ of $5 \%$ sulfuric acid and frozen at $-20^{\circ} \mathrm{C}$ until analysis for VFA and ammonia-N. After thawing, $5 \mathrm{~mL}$ of rumen fluid was vortexed with $1 \mathrm{~mL}$ of $250 \mathrm{~g} / \mathrm{L}$ of meta-phosphoric acid and centrifuged at $3,000 \times g$ for $20 \mathrm{~min}$ at $4^{\circ} \mathrm{C}$ to separate the supernatants. The VFA were determined by gas chromatography on a Chrompack CP 9002, model no. CP-9002 (Vulcanusweg 259, 2600 AM, Delft, the Netherlands) with a $50 \mathrm{~m}$ (0.32 mm ID) silica-fused

Table 1. Nutrient and fatty acid content of safflower seeds fed at 3 levels to mid-lactation dairy cows

\begin{tabular}{lr}
\hline Item & Value \\
\hline Nutrient & \\
DM (\%) & 93.0 \\
CP $\%$ of DM) & 19.5 \\
NDF (\% of DM) & 38.1 \\
ADF (\% of DM) & 29.7 \\
EE (\% of DM) & 40.2 \\
Ash (\% of DM) & 1.2 \\
Fatty acid (\% of EE) & 97.5 \\
Fatty acid $\left.{ }^{2} \%\right)$ & \\
C14:0 & 1.2 \\
C16:0 $18: 0$ & 5.5 \\
C18:1 $18: 2$ & 2.2 \\
C18:3 13.2 \\
Others ${ }^{3}$ & 14.0 \\
\hline
\end{tabular}

${ }^{1} \mathrm{EE}=$ ether extract, a measure of crude fat.

${ }^{2}$ Fatty acids expressed as number of carbons:number of double bonds. ${ }^{3}$ Others determined by difference $(100-\Sigma$ fatty acids determined). 
Table 2. Ingredient content and mean dietary nutrient content of diets containing 3 levels of rolled safflower seed

\begin{tabular}{|c|c|c|c|}
\hline \multirow[b]{2}{*}{ Item } & \multicolumn{3}{|c|}{ Dietary treatment ${ }^{1}$} \\
\hline & SS0 & $\mathrm{SS} 3$ & SS6 \\
\hline \multicolumn{4}{|l|}{ Ingredient (\% of DM) } \\
\hline Alfalfa hay & 19.9 & 19.9 & 19.9 \\
\hline Corn silage & 19.6 & 19.6 & 19.6 \\
\hline Barley grain, ground & 22.9 & 22.9 & 22.9 \\
\hline Corn, dried, shell, ground & 7.2 & 7.2 & 7.2 \\
\hline Cottonseed, whole & 10.2 & 7.2 & 4.2 \\
\hline Safflower seeds, whole rolled & 0.0 & 3.0 & 6.0 \\
\hline Cottonseed meal & 6.6 & 6.6 & 6.6 \\
\hline Soybean meal & 7.4 & 7.4 & 7.4 \\
\hline Wheat bran & 4.6 & 4.6 & 4.6 \\
\hline Mineral/vitamin premix ${ }^{2}$ & 0.2 & 0.2 & 0.2 \\
\hline Salt, white & 0.2 & 0.2 & 0.2 \\
\hline Sodium bicarbonate & 0.6 & 0.6 & 0.6 \\
\hline Dicalcium phosphate & 0.2 & 0.2 & 0.2 \\
\hline Limestone, ground & 0.4 & 0.4 & 0.4 \\
\hline \multicolumn{4}{|c|}{ Nutrient composition, DM basis (mean $\pm \mathrm{SD}$ ) } \\
\hline $\mathrm{NE}_{\mathrm{L}}^{3}(\mathrm{Mcal} / \mathrm{kg})$ & $1.56 \pm 0.7$ & $1.59 \pm 0.4$ & $1.62 \pm 0.7$ \\
\hline $\mathrm{CP}(\%$ of $\mathrm{DM})$ & $16.4 \pm 0.2$ & $16.3 \pm 0.1$ & $16.2 \pm 0.1$ \\
\hline $\mathrm{ADF}(\%$ of $\mathrm{DM})$ & $23.3 \pm 0.3$ & $23.2 \pm 0.2$ & $23.1 \pm 0.2$ \\
\hline $\mathrm{NDF}(\%$ of DM) & $36.0 \pm 0.2$ & $35.8 \pm 0.2$ & $35.7 \pm 0.1$ \\
\hline NFC ( $\%$ of DM) & $40.0 \pm 0.3$ & $39.9 \pm 0.2$ & $39.8 \pm 0.4$ \\
\hline $\mathrm{EE}^{4}(\%$ of $\mathrm{DM})$ & $3.90 \pm 0.2$ & $4.3 \pm 0.3$ & $4.7 \pm 0.2$ \\
\hline Ash (\% of DM) & $1.1 \pm 0.1$ & $1.1 \pm 0.1$ & $1.1 \pm 0.2$ \\
\hline Fatty acids (\% of EE) & $85.3 \pm 4.3$ & $86.5 \pm 6.0$ & $87.8 \pm 3.7$ \\
\hline
\end{tabular}

${ }^{1} \mathrm{SS} 0$, SS3, SS6 $=$ dietary treatments of 0,3 , and $6 \%$ rolled whole safflower seeds, respectively.

${ }^{2}$ Premix contained per kilogram of premix: $193 \mathrm{~g}$ of $\mathrm{Ca}, 97 \mathrm{~g}$ of P, $76 \mathrm{~g}$ of Na, $16 \mathrm{~g} \mathrm{of} \mathrm{Mg}, 3 \mathrm{~g}$ of Fe, $0.3 \mathrm{~g}$ of $\mathrm{Cu}, 2.66 \mathrm{~g}$ of Mn, $100 \mathrm{mg} / \mathrm{kg}$ of Co, $100 \mathrm{mg} / \mathrm{kg}$ of I, $0.1 \mathrm{mg} / \mathrm{kg}$ of Se, and $5.0 \times 10^{6} \mathrm{IU}$ of vitamin A, $1.0 \times 10^{6}$

$\mathrm{IU}$ of vitamin $\mathrm{D}$, and $0.1 \mathrm{~g}$ of vitamin $\mathrm{E}$.

${ }^{3}$ Calculated per NRC (2001).

${ }^{4} \mathrm{EE}=$ ether extract.

column (CP-Wax Chrompack Capillary Column, Varian, Palo Alto, CA). Helium was the carrier gas, and initial and final temperatures were set at 55 and $195^{\circ} \mathrm{C}$, respectively, with detector and injector temperatures set at $250^{\circ} \mathrm{C}$. Crotonic acid $(1: 7, \mathrm{vol} / \mathrm{vol})$ was used as internal standard. Ammonia nitrogen was determined by a colorimetric phenol-hypochlorite method according to Broderick and Kang (1980).

Lipids were extracted from $10.0 \mathrm{~g}$ of dried TMR samples using $100 \mathrm{~mL}$ of chloroform:methanol (2:1,

Table 3. Fatty acid composition of the diets containing 3 levels of DM as rolled safflower seed

\begin{tabular}{|c|c|c|c|c|c|c|}
\hline \multirow{2}{*}{$\begin{array}{l}\text { Fatty acid }{ }^{1} \\
(\mathrm{~g} / 100 \mathrm{~g} \text { of } \mathrm{FAME})\end{array}$} & \multicolumn{3}{|c|}{ Dietary treatment ${ }^{2}$} & \multirow[b]{2}{*}{$\mathrm{SE}$} & \multicolumn{2}{|c|}{$P$-value } \\
\hline & SS0 & SS3 & SS6 & & $\mathrm{SS}^{3}$ & Level $^{4}$ \\
\hline C14:0 & $6.9^{\mathrm{a}}$ & $6.5^{\mathrm{b}}$ & $6.5^{\mathrm{b}}$ & 0.03 & $<0.001$ & 0.60 \\
\hline C16:0 & $14.3^{\mathrm{a}}$ & $13.2^{\mathrm{b}}$ & $12.5^{\mathrm{c}}$ & 0.07 & $<0.001$ & 0.01 \\
\hline C18:0 & $2.1^{\mathrm{a}}$ & $1.2^{\mathrm{b}}$ & $0.8^{\mathrm{c}}$ & 0.12 & $<0.001$ & $<0.001$ \\
\hline C18:1 & $14.2^{\mathrm{a}}$ & $13.8^{\mathrm{b}}$ & $13.3^{\mathrm{c}}$ & 0.04 & 0.01 & 0.03 \\
\hline C18:2 & $27.9^{\mathrm{c}}$ & $40.4^{\mathrm{b}}$ & $52.4^{\mathrm{a}}$ & 0.45 & $<0.001$ & $<0.001$ \\
\hline $\mathrm{C} 18: 3$ & $6.8^{\mathrm{a}}$ & $6.1^{\mathrm{b}}$ & $4.9^{\mathrm{c}}$ & 0.11 & $<0.001$ & $<0.001$ \\
\hline $\mathrm{C} 22: 0$ & $0.4^{\mathrm{a}}$ & $0.3^{\mathrm{b}}$ & $0.3^{\mathrm{b}}$ & 0.04 & $<0.001$ & 0.67 \\
\hline $\mathrm{C} 24: 0$ & 0.2 & 0.2 & 0.2 & 0.01 & 0.94 & 0.16 \\
\hline
\end{tabular}

${ }^{a-c}$ Means within a row that do not have a common superscript differ at $P<0.05$.

${ }^{1}$ Fatty acid expressed as number of carbon atoms:number of double bonds.

${ }^{2} \mathrm{SS} 0, \mathrm{SS} 3, \mathrm{SS} 6=$ dietary treatments of 0,3 , and $6 \%$ rolled whole safflower seeds, respectively.

${ }^{3} \mathrm{SS}=$ probability of a difference between diets with safflower seeds in diet compared with diet with no safflower seed.

${ }^{4}$ Level $=$ probability of a difference between diet with $3 \%$ added safflower seed compared with diet with $6 \%$. 
vol:vol; Folch et al., 1957) in experimental wk 1, 3, 5, and 8 , coinciding with milk FA analysis after drying and grinding to pass through a 2 -mm screen in a Wiley mill. Samples were vortexed for $5 \mathrm{~min}$ and allow to sit for another $30 \mathrm{~min}$. Following separation of layers by addition of $6 \% \mathrm{NaCl}$, the chloroform layer was removed and the sample re-extracted and combined with the first extraction. The extracted sample was dried under $\mathrm{N}_{2}$ gas, extracted with $4 \mathrm{~mL}$ of hexane, and saponified with $1 \mathrm{~mL}$ of a $0.6 \%$ solution of $\mathrm{KOH}$ in methanol. Free FA were dried under $\mathrm{N}_{2}$, weighed, then taken up in $2 \mathrm{~mL}$ of hexane for storage in a capped vial until methylation. Milk fat was extracted by boiling milk in a detergent solution (Hurley et al., 1987). For both feed and milk, extracted fat was converted to methyl esters by mixing $40 \mathrm{mg}$ of fat with a $\mathrm{NaOCH}_{3}$ in methanol reagent as described by Chouinard et al. (1999). After methylation, anhydrous $\mathrm{CaCl}_{2}$ was added and allowed to stand for $1 \mathrm{~h}$ to remove any water in the sample. Samples were then centrifuged at 1,016 $\times g$ for $20 \mathrm{~min}$ at $4^{\circ} \mathrm{C}$ and the supernatant removed. Methyl esters from all samples were taken up in $1 \mathrm{~mL}$ of hexane and $1 \mu \mathrm{L}$ was injected onto a CP-Sil 88 fused silica 100 $\times 0.25 \mathrm{~mm}$ column (Varian Inc., Palo Alto, CA) in a model 6890 gas chromatograph (Hewlett Packard Co., Avondale, PA) fitted with a flame ionization detector and with a 1:100 split injection adjustment. The initial column temperature was $80^{\circ} \mathrm{C}$, which was increased at $12^{\circ} \mathrm{C}$ per min until reaching $190^{\circ} \mathrm{C}$, whereas the injector and detector temperatures were held at $250^{\circ} \mathrm{C}$. Heptadecanoic acid was used as the internal standard. Fatty acids are reported as percentage of FAME.

\section{Calculations and Statistical Analysis}

Fat-corrected milk was calculated as per NRC (2001), and ECM was calculated using the equation of Rico et al. (2014). Statistical evaluation of SCC was performed after log-transformation, but the data were re-converted to standard SCC for presentation. Intake of nutrient components was calculated as DMI $(\mathrm{kg}) \times$ nutrient (\% DM). Individual FA intake was calculated as DMI $(\mathrm{kg}) \times \mathrm{EE}(\% \mathrm{DM}) \times$ total $\mathrm{FA}(\% \mathrm{EE}) \times$ individual FA ( $\%$ FA). Milk FA yield was calculated as $\operatorname{MFY}(\mathrm{g} / \mathrm{d}) \times 0.933 \times$ milk FA $(\%)$ as suggested by Glasser et al. (2007). The C6:0 to C11:0 FA were arbitrarily grouped as short-chain FA (SCFA) for ease of discussion. The FA from C12:0 to C16:1 were defined as the medium-chain FA (MCFA), whereas the longchain FA (LCFA) were defined as C17:0 and greater. Monounsaturated fatty acids were calculated as the sum of $[\mathrm{C} 15: 1+\mathrm{C} 16: 1+\mathrm{C} 17: 1$ and $\mathrm{C} 18: 1]$, whereas PUFA were calculated as the sum of $[\mathrm{CLA}+\mathrm{n}-3+$ n-6]. The n-3 were calculated as the sum of n-3 FA, and n-6 was calculated as the sum of n-6 FA.

Calculation of desaturase index (DSI) was as suggested by Kelsey et al. (2003) where DSI $=$ [product of $\Delta^{9}$-desaturase]/[product of $\Delta^{9}$-desaturase + substrate of $\Delta^{9}$-desaturase]. Linear slope coefficients were calculated through the weekly means using Excel 2016. Before the statistical evaluation, all data were tested for normality in SAS (Release 9.0, SAS Institute Inc., Cary, NC; PROC UNIVARIATE plot normal), and all parameters followed a normal distribution. Data were analyzed as a randomized block design with a repeated measure of treatment structure using the PROC MIXED procedure of SAS release 9.0 (SAS Institute Inc., Cary, NC). A different covariance matrix structure based on Akaike's information criterion and the Kenward-Roger option to estimate denominator degrees of freedom were developed for each variable. The model included terms for dietary treatment (diet), parity, week of treatment (the repeated measure), diet $\times$ parity, diet $\times$ week, and the 3-way interaction. Cow nested with diet and parity was considered a random factor whereas treatment, parity, and week of treatment, and their interactions were considered fixed effects. Two orthogonal contrasts were used to test the effect of treatment: SS0 versus SS3 + SS6 (effect of SS) and SS3 versus SS6 (effect of SS level). Data are presented as the $\mathrm{LSM} \pm \mathrm{SE}$ with diet $\times$ week the variable of greatest interest. Significance was declared at $P \leq 0.05$ and trends discussed at $P \leq 0.10$.

\section{RESULTS}

\section{General Features}

Although several interactions between diet $\times$ week $\times$ parity were detected, they appeared to have no biological explanation and therefore will not be discussed, although they are noted in Tables 4,5 , and 6 . There were few diet $\times$ parity interactions for changes in milk FA.

Although at the day before trial began, the milk production was not different among treatments, milk yield (MY) was greater for cows fed SS than SS0, and cows fed SS6 produced more milk than cows fed SS3 (Table 4). However, the MFPct, true milk protein $\%$, lactose \%, MFY, and yield of milk true protein, and milk lactose as well as 4\% FCM and ECM were not different among diets. Total yields of these components did show a parity $\times$ week interaction. These interactions were all caused by a more rapid decline in the weekly MY of multiparous cows compared with primiparous cows (data not shown). For cows fed SS6 the yields of all milk components were maintained at a 
Table 4. Effect of graded levels of safflower seed fed to lactating cows on milk production, nutrient intake, and digestibility variables

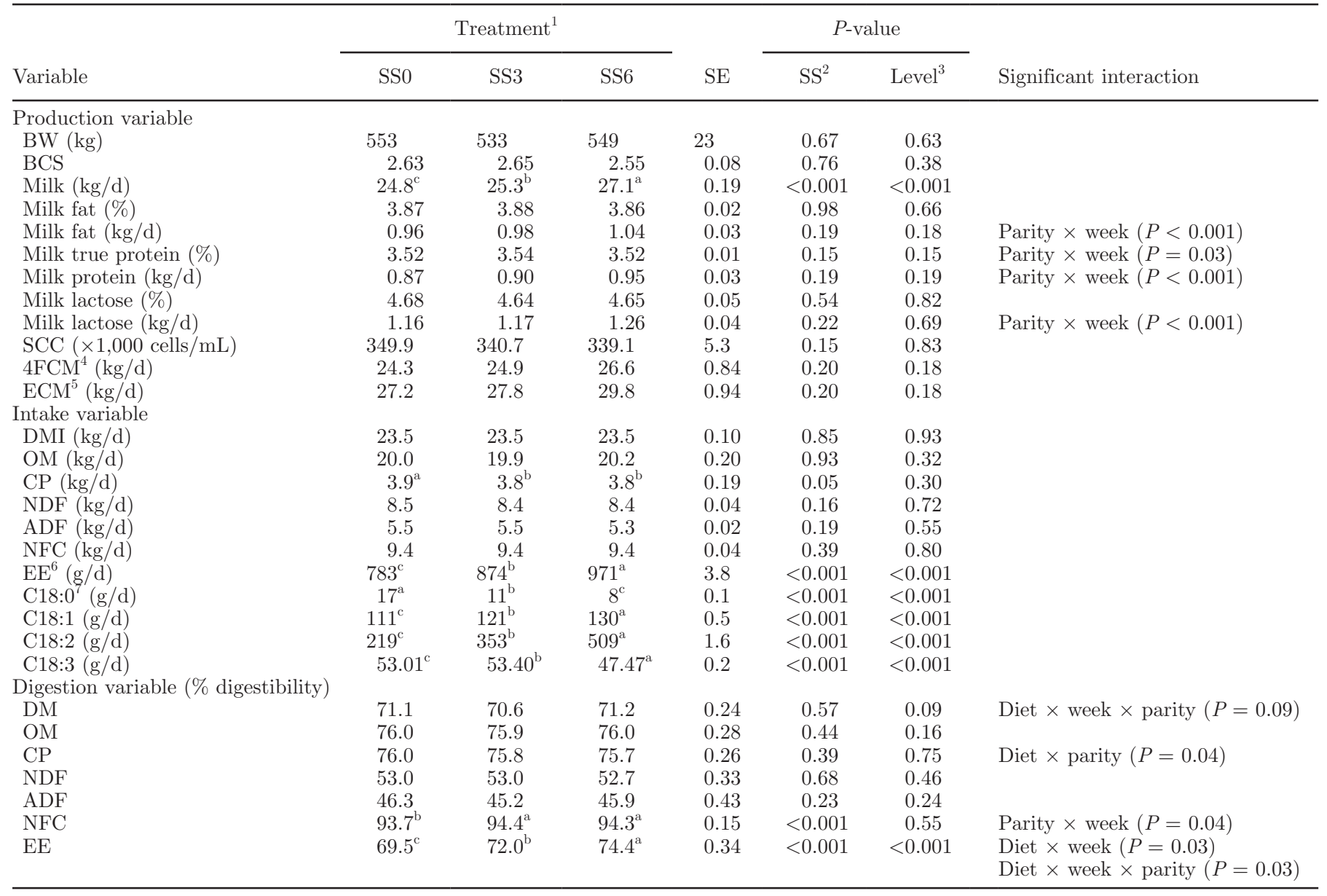

${ }^{\mathrm{a}-\mathrm{c}}$ Means within a row that do not have a common superscript differ at $P<0.05$.

${ }^{1} \mathrm{SS} 0, \mathrm{SS} 3, \mathrm{SS} 6=$ dietary treatments of 0,3 , and $6 \%$ rolled whole safflower seeds, respectively.

${ }^{2} \mathrm{SS}=$ probability of a difference between diets with safflower seeds in diet compared with diet with no safflower seed.

${ }^{3}$ Level $=$ probability of a difference between diet with $3 \%$ added safflower seed compared with diet with $6 \%$.

${ }^{4} 4 \mathrm{FCM}=4 \% \mathrm{FCM}$, calculated according to NRC, 2001.

${ }^{5} \mathrm{ECM}$ calculated according to Rico et al., 2014.

${ }^{6} \mathrm{EE}=$ ether extract.

${ }^{7}$ Fatty acid expressed as number of carbon atoms:number of double bonds.

Table 5. Effect of graded levels of safflower seed fed to lactating cows on rumen function variables

\begin{tabular}{|c|c|c|c|c|c|c|c|}
\hline Variable & \multicolumn{3}{|c|}{ Treatment $^{1}$} & $\mathrm{SE}$ & \multicolumn{2}{|c|}{$P$-value } & Significant interaction \\
\hline $\mathrm{pH}$ & 6.53 & 6.54 & 6.53 & 0.01 & 0.49 & 0.84 & \\
\hline Acetate $(\mathrm{mol} / 100 \mathrm{~mol})$ & 67.9 & 67.8 & 67.8 & 0.08 & 0.21 & 0.25 & \\
\hline Propionate $(\mathrm{mol} / 100 \mathrm{~mol})$ & 19.6 & 19.6 & 19.6 & 0.07 & 0.21 & 0.93 & \\
\hline Butyrate (mol/100 mol) & 9.1 & 9.1 & 9.1 & 0.05 & 0.82 & 0.44 & \\
\hline Iso-valerate $(\mathrm{mol} / 100 \mathrm{~mol})$ & 0.8 & 0.8 & 0.8 & 0.02 & 0.26 & 0.41 & \\
\hline
\end{tabular}

${ }^{1} \mathrm{SS} 0, \mathrm{SS} 3, \mathrm{SS} 6$ = dietary treatments of 0,3 , and $6 \%$ rolled whole safflower seeds, respectively.

${ }^{2} \mathrm{SS}=$ probability of a difference between diets with safflower seeds in diet compared with diet with no safflower seed.

${ }^{3}$ Level $=$ probability of a difference between diet with $3 \%$ added safflower seed compared with diet with $6 \%$. 
level considerably greater than either SS0 or SS3 due to greater milk yield with cows fed SS3 intermediate in production level between SS0 and SS6. A parity $\times$ week interaction was found for milk true protein \% (Table 4), which appeared to be caused by primiparous cows having a higher milk protein $\%$ than multiparous cows

Table 6. The effect of graded levels of safflower seed on the percentage of fatty acids in milk fat of dairy cows fed rolled safflower seed

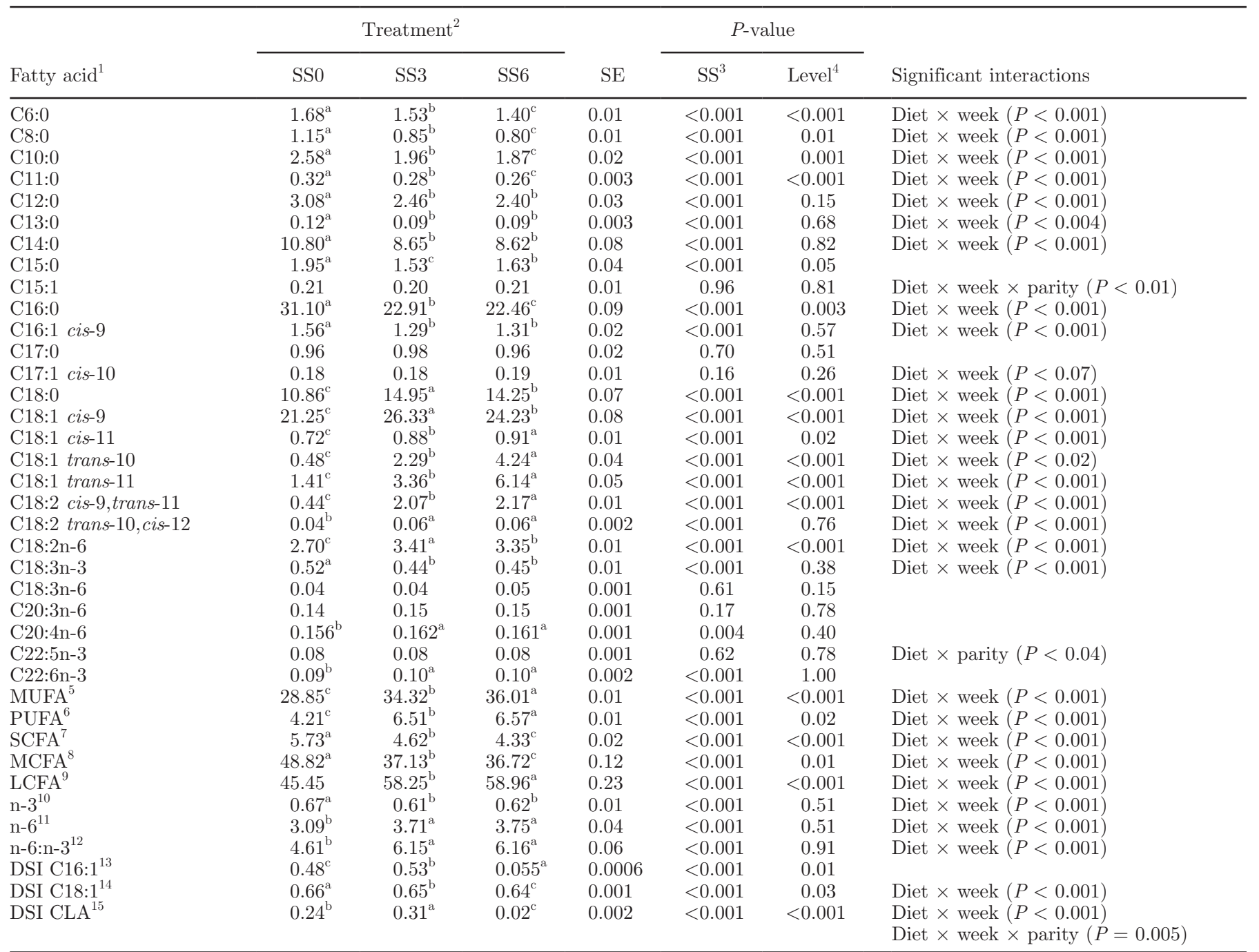

\footnotetext{
${ }^{\mathrm{a}-\mathrm{c}}$ Means within a row that do not have a common superscript differ at $P<0.05$.

${ }^{1}$ Expressed as number of carbon atoms:number of double bonds.

${ }^{2} \mathrm{SS} 0, \mathrm{SS} 3, \mathrm{SS} 6=$ dietary treatments of 0,3 , and $6 \%$ rolled whole safflower seeds, respectively.

${ }^{3} \mathrm{SS}=$ probability of a difference between diets with safflower seeds in diet compared with diet with no safflower seed.

${ }^{4}$ Level $=$ probability of a difference between diet with $3 \%$ added safflower seed compared with diet with $6 \%$.

${ }^{5} \mathrm{MUFA}=$ sum of $\mathrm{C} 15: 1, \mathrm{C} 16: 1, \mathrm{C} 17: 1$, and $\mathrm{C} 18: 1$.

${ }^{6} \mathrm{PUFA}=$ sum of CLA, n-3, and n-6 fatty acids.

${ }^{7} \mathrm{SCFA}=$ short-chain fatty acids, sum of C6:0 to C11:0 fatty acids.

${ }^{8} \mathrm{MCFA}=$ medium-chain fatty acids, sum of C12:0 to C16:1 fatty acids.

${ }^{9} \mathrm{LCFA}=$ long-chain fatty acids, sum of all fatty acids $\mathrm{C} 18$ and greater.

${ }^{10} \mathrm{n}-3=$ sum of $\mathrm{n}-3$ fatty acids.

${ }^{11} \mathrm{n}-6=$ sum of $\mathrm{n}-6$ fatty acids

${ }^{12} \mathrm{n}-6: \mathrm{n}-3=$ sum of $\mathrm{n}-6 /$ sum of $\mathrm{n}-3$.

${ }^{13}$ DSI C16:1 = desaturation index for C16:1 [C16:1 cis-9/(C16:1 cis-9 + C16:0)].

${ }^{14} \mathrm{DSI}$ C18:1 = desaturation index for $\mathrm{C} 18: 1[\mathrm{C} 18: 1$ cis-9/(C18:1 cis-9 $\left.+\mathrm{C} 18: 0)\right]$.

${ }^{15}$ DSI CLA $=$ desaturation index for CLA [C18:2 cis-9 trans-11/(C18:2 cis-9 trans-11 + C18:1 trans-11)].
} 
at wk 2, 3, 4, 6, and 7 assuming trends in measured weeks were continued, but a lower milk protein $\%$ for wk 1,5 , and 8 .

Consumption of CP was greater for cows fed SS0 compared with SS3 and SS6, whereas fat intake was lower in SS0 and gradually increased in SS3 and SS6 (Table 4). Mean DMI, NDF, and NFC intakes were not different among dietary treatments. As planned, the consumption of EE was greater for cows fed SS than cows fed SS0, with cows fed SS6 consuming $100 \mathrm{~g}$ more EE more than those fed SS3, and cows consuming diet SS3 consuming $90 \mathrm{~g}$ more than those fed SS0 (Table 4). Because SS replaced whole cottonseed, C18:0 and C18:3 consumptions were less for cows fed SS, and cows fed SS6 consumed less C18:0 and C18:3 than cows fed SS3. Conversely, consumption of C18:1 and C18:2 was greater for cows fed SS, and cows fed SS6 had greater consumption of $\mathrm{C} 18: 1$ and $\mathrm{C} 18: 3$ than cows fed SS3 (Table 4). In summary, cows consumed 0.00, 0.705, and $1.410 \mathrm{~kg}$ of SS, and therefore $0.00,0.283$, and $0.567 \mathrm{~kg}$ of fat from SS for diets SS0, SS3, and SS6, respectively. In turn, cows consumed 111, 121, and $130 \mathrm{~g}$ of C18:1, 219,353 , and $509 \mathrm{~g}$ of $\mathrm{C} 18: 2$, and 53,53 , and $48 \mathrm{~g}$ of C18:3 for dietary treatments SS0, SS3, and SS6 from all feed sources, respectively (Table 4). The intakes of SS, EE, and these FA were different among diets as well as between SS3 and SS6 $(P<0.001)$. In general, consumption of nutrients was greater for multiparous cows than primiparous cows. Moreover, DM consumption, MY, MFY, yields of milk true protein and lactose declined slightly with advancing weeks as would be expected (data not shown).

The digestibility of NFC and EE were greater for cows fed SS. However, only EE digestibility was different between levels of SS, with cows fed SS6 having greater EE digestibility than cows fed SS3. However, digestibilities of DM and OM, as well as NDF were not different among diets, although there was a trend for OM digestion to be greater in cows fed SS6 than SS3. Rumen function variables were not different due to diet, although a trend was present for an interaction between diet and parity for ammonia nitrogen (Table 5). This interaction was caused by the fact that ammonia $\mathrm{N}$ was the same for SS0 in the rumen of both parities, but was higher for primiparous cows fed SS3 than multiparous cows when fed SS3, whereas ammonia $\mathrm{N}$ was lower in the rumens of primiparous cows than multiparous cows when fed SS6.

\section{Milk Fatty Acids}

The FA distribution in milk fat among diets is presented in Table 6 . There were seldom parity effects associated with FA distribution. There were strong diet and diet $\times$ week interactions for all $\mathrm{FA}(P<0.05)$ except for C:15, C15:1, C18:3n-6, C20:3n-6, C20:4n-6, $\mathrm{C} 22: 5 \mathrm{n}-3$, and $\mathrm{C} 22: 6 \mathrm{n}-3$ where no interactions were detected. Also, C17:1 cis-10 showed no significant treatment effects and only a trend toward a treatment $\times$ week effect $(P=0.07)$. The $\%$ of $\mathrm{C} 20: 4 \mathrm{n}-6$ and C22:6n-3 in milk were both increased by the presence of SS in the diet, but not by the amount of SS in the diet. Overall, both n-6 FA and n-6:n-3 ratio were increased in a linear fashion when feeding higher levels of SS (Table 6). The C15:0 in milk fat was decreased by feeding SS, although the percentage was greater in the milk of cows fed SS6 than those fed SS3, whereas C15:1 was not affected. These FA were all minor constituents in the milk fat (Table 6).

The more abundant FA were more consistently affected by SS feeding with cows fed SS0 displaying little change in milk FA composition over the 8 weeks of the experiment. The percent of C8:0 in milk declined from wk 1 to 3 for cows fed SS. Thereafter C8:0 declined more rapidly until wk 5 at which point the rate of decline was less than the decline in wk 5 to 8 of the experiment (Table 7, Figure 1B). When cows were fed SS, all other FA, whether they declined or increased, remained more or less steady until after wk 3 .

The C6:0 in milk fat remained basically unchanged until wk 3 at which point it declined linearly for cows fed SS, with a steeper decline in milk from cows fed SS6 than SS3 (Table 7, Figure 1A). The C10:0 and C11:0 FA in milk decreased after 3 wk of feeding SS, but in wk 5 through 8 tended to remain constant in the milk of cows fed SS3, but continued to decline when cows were fed SS6 (Table 7, Figure 1C and D). For cows fed SS, the milk FA levels of C12:0 through C16:1 cis-9 remained steady from wk 1 to 3 , declined from wk 3 to 5 , and then remained steady at the lower levels from wk 5 to 8 (Table 7, Figure 2A, B, C, D, and E). The C18:0, C18:1 cis-9, C18:1 cis-11, C18:1 trans-10, C18:1 trans-11, C18:2 cis-9,trans-11, C18:2 trans-10,cis-12, C18:2n-3, and C18:3n-6 remained steady from wk 1 to 3 , increased from wk 3 to 5 , and then remained steady from wk 5 to 8 when cows were fed SS (Table 7, Figure $3 \mathrm{~A}$ to $\mathrm{J}$ ). Although differences between these FA in the milk from cows fed SS3 and SS6 are significant (Table 6), graphically these differences appear to be very small. Of the long-chain FA, only C18:3n-3 decreased in the milk fat in response to SS feeding (Table 7, Figure 4), and this FA displayed a response much like the C12-C16:1 FA.

Although the C16:1 concentration in milk fat from cows fed SS decreased, other MUFA increased such that MUFA increased for cows fed SS $(\sim 33 \%$ increase; Table 6 ). From the viewpoint of time of feeding, the total MUFA were similar to the LCFA, remaining constant 
TEMPORAL CHANGES IN MILK FATTY ACID PROFILE

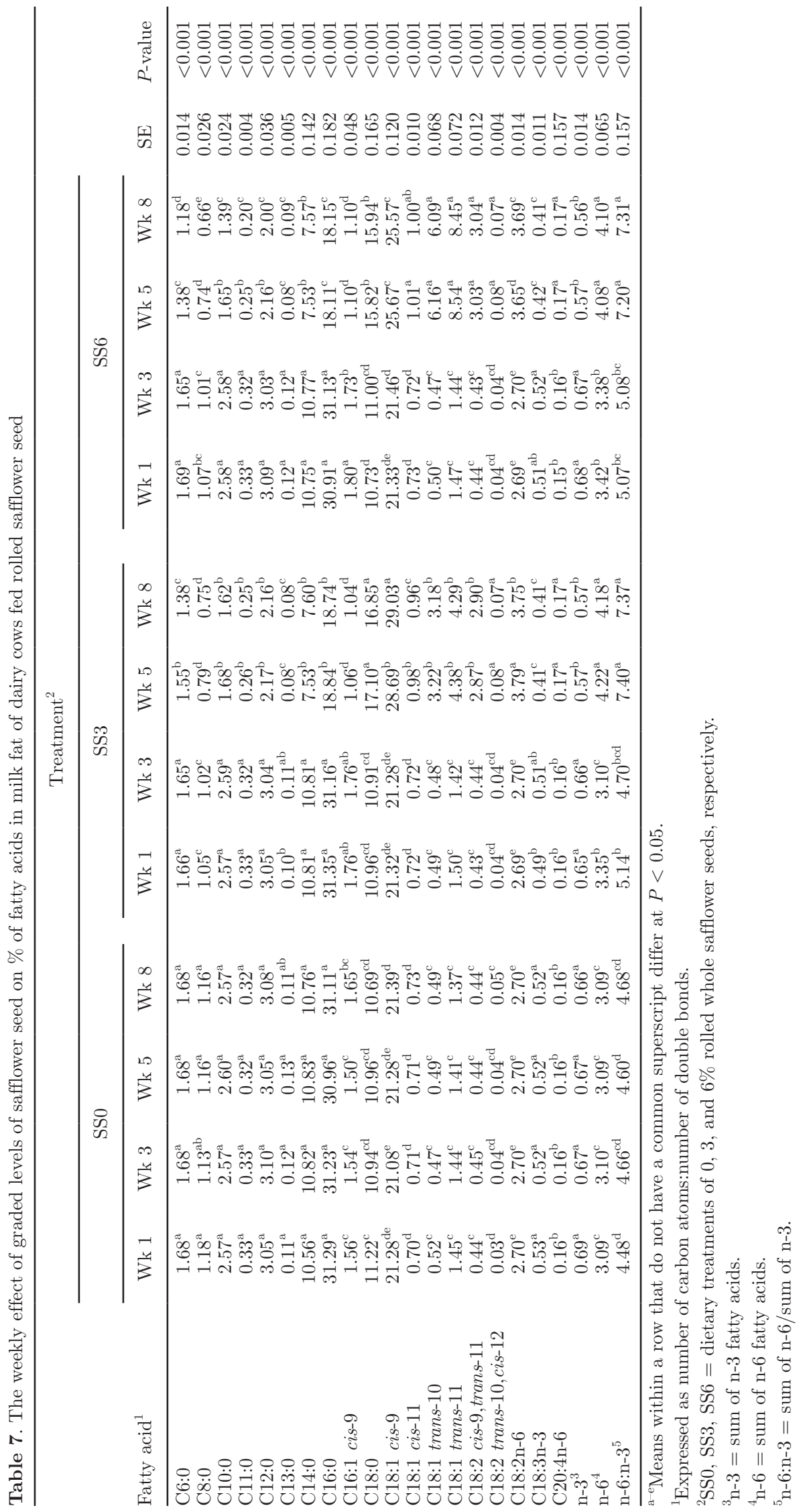



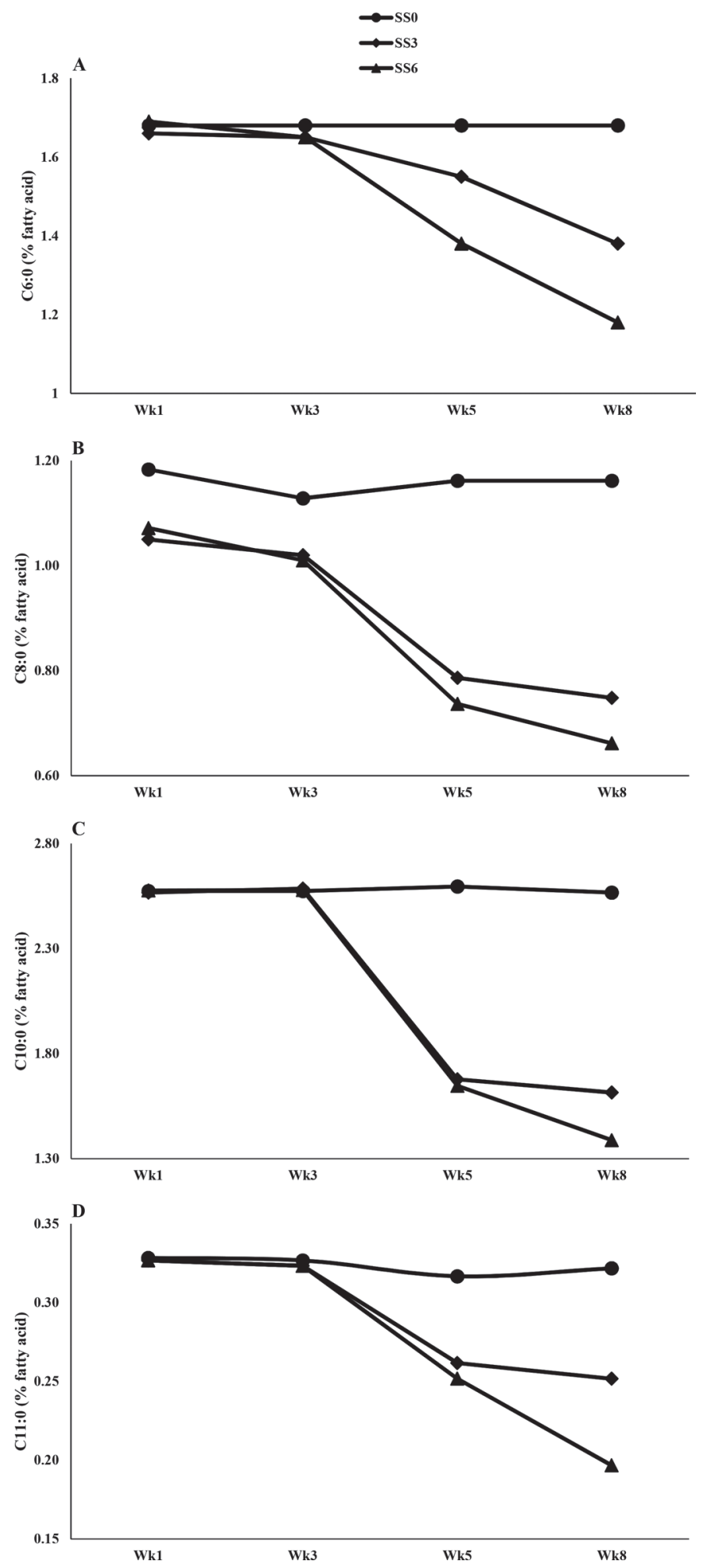

Figure 1. Changes in short-chain fatty acids with significant diet $\times$ week interactions (A, C6:0; B, C8:0; C, C10:0; D, C11:0) \% of total fatty acids expressed as methyl esters in milk of cows fed 3 levels of rolled safflower seed. SS0, SS3, SS6: dietary treatments of 0, 3, and $6 \%$ rolled whole safflower seeds, respectively. Analyses were conducted separately for each week. The SE ranged from 0.44 to $2.56 \%$. for the first $3 \mathrm{wk}$, then increasing in wk 3 to 5 , and then remaining constant in wk 5 to 8 (graph not shown). The PUFA followed a very similar pattern to MUFA and LCFA, increasing by approximately 24 and $48 \%$ in the milk from cows fed SS3 and SS6, respectively. Generally, the MCFA concentration in milk followed a pattern which was a mirror opposite of the LCFA, remaining constant for the first 3 wk of SS feeding, but displaying a large drop between wk 3 to 5. Cows fed SS3 tended to maintain this concentration of MCFA, whereas cows fed SS6 tended to continue the decline in concentration of MCFA (graph not shown). The total n-3 FA concentration decreased from wk 3 to 5 and then remained steady from wk 5 to 8 (Table 7 , Figure 4A), whereas the total n- 6 FA concentration increased from wk 3 to 5 and then remained steady to the end of the study (Table 7, Figure 4B). These events resulted in the milk from SS-fed cows having a slightly higher n-6:n-3 ratio from wk 1 to 3 , followed by a steep rise from wk 3 to 5 and a steady ratio from wh 5 to 8 (Table 7, Figure $4 \mathrm{C})$. The overall increase in n- $6 \mathrm{FA}$ was $35 \%$, whereas the overall increase in n-6:n-3 was approximately $60 \%$, and the n-3 FA decreased approximately $15 \%$.

The DSI for C16:1 (DSI C16:1) was greater for cows fed SS than cows fed SS0, and the SS6 diet was greater than SS3. An interaction between diet and parity was detected also. Basically this was due to the primiparous cows having a lower DSI C16:1 than multiparous cows when they were fed the SS0 diet; however, the DSI C16:1 was approximately equal between parities on the SS3 diet, whereas the primiparous cows fed SS6 had a higher DSIC16 than did multiparous cows (graph not shown). The DSI for C18:1 (DSI C18:1) displayed a significant diet $\times$ week interaction as did the DSI for CLA (DSI CLA). Cows fed SS0 displayed a slight increase in DSI C18:1 over the time of the experiment, whereas cows fed SS3 decreased DSI C18:1 sharply from wk 3, reaching a nadir at wk 5 before trending upward (Figure 5A). Cows fed SS6 followed a similar pattern in DSI C18:1 to those fed SS3 through wk 5 but declined from wk 5 to 8 in comparison to the increased DSI C18:1 for SS3. The DSI CLA in milk showed no change until wk 3, at which time the DSI CLA increased greatly for cows fed SS3, but only slightly for cows fed SS6. Both SS diets maintained the DSI CLA from wk 5 through 8 (Figure 5B).

\section{DISCUSSION}

In this study, SCFA and MCFA were decreased, whereas LCFA, particularly C18:1 (both cis and trans) and C18:2 FA (both CLA and n-6), increased significantly. Additionally, total n-3 FA decreased in milk FA, whereas n-6 FA increased. The changes in milk CLA 
are consistent with other experiments where milk CLA is increased by abomasal CLA infusion (Chouinard et al., 1999; Perfield et al., 2004), feeding of plant oils and plant seeds (Roy et al., 2006; Bu et al., 2007), or both (Huang et al., 2008) with the exception that in those studies, the changes in FA composition were accompanied by a decrease in MFPct and MFY. Observed changes in n-3 and n- 6 FA were also as found when feeding oil seeds or oil (Roy et al., 2006; Shingfield et al., 2006). The decrease in MFPct and MFY reported in those studies was not observed in our study, although changes in CLA, n-3, and n-6 were also not as large.
This may be due to higher levels of fat and CLA in their studies, difficulty digesting SS (Godfrey, 2007) such that oil was not liberated from the seed for rumen bio-hydrogenation, or that the relatively small cow numbers made accurate detection difficult. Also, the whole seeds of oil-producing plants do not seem to be as effective as free oil in provoking a CLA response (Dhiman et al., 2000). However, the present study, along with those of Dschaak et al. (2010), indicate that when SS are fed at levels between 1 and $3 \%$ of DM, CLA content of milk can be increased without loss of milk fat production.
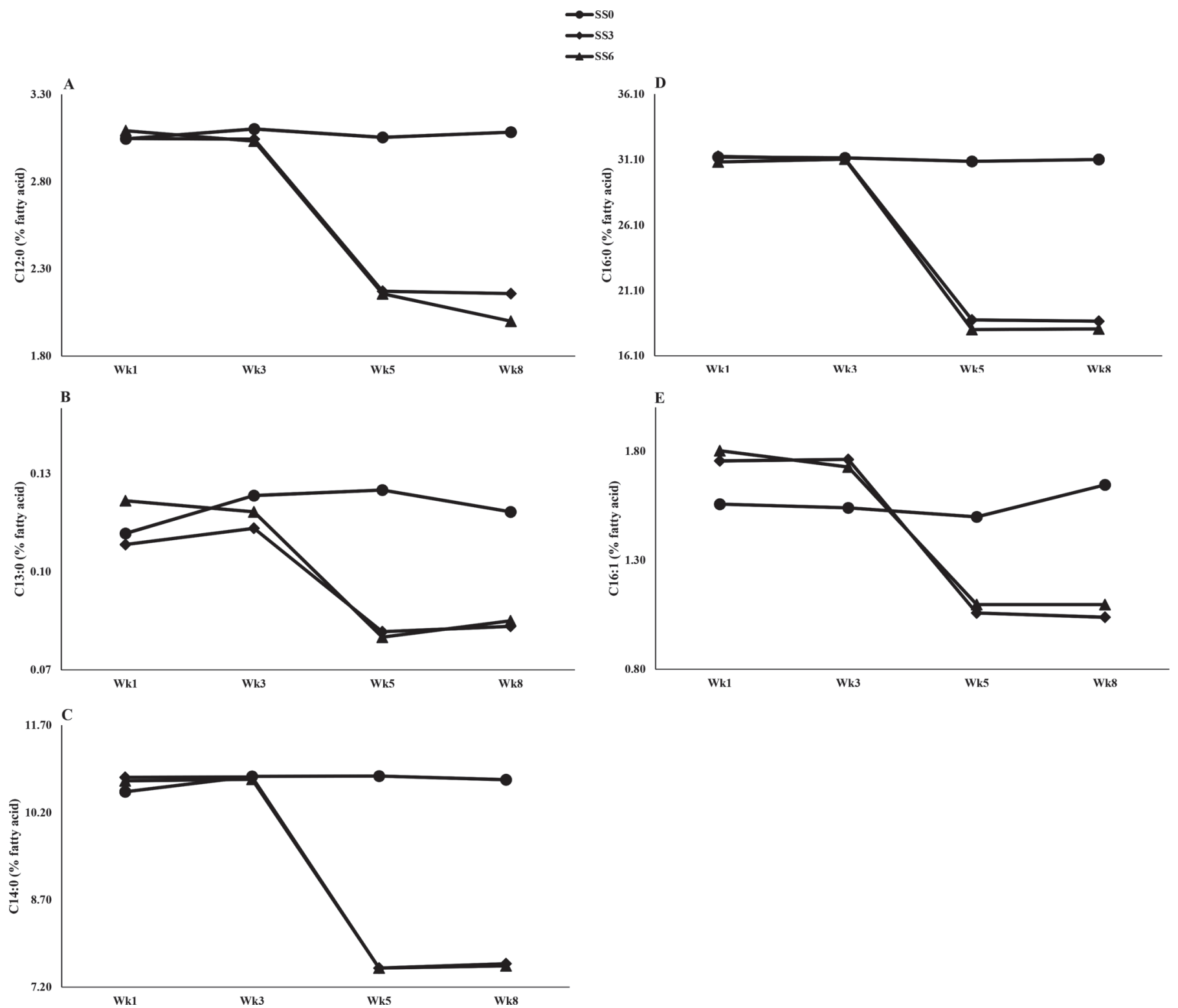

Figure 2. Changes in medium-chain fatty acids with significant diet $\times$ week interactions (A, C:12:0; B, C13:0; C, C14:0; D, C16:0; E, C16:1 cis-9) \% of total fatty acids expressed as methyl esters in milk of cows fed 3 levels of rolled safflower seed. SS0, SS3, SS6: dietary treatments of 0,3 , and $6 \%$ rolled whole safflower seeds, respectively. Analyses were conducted separately for each week. The SE ranged from 0.53 to $4.76 \%$. 

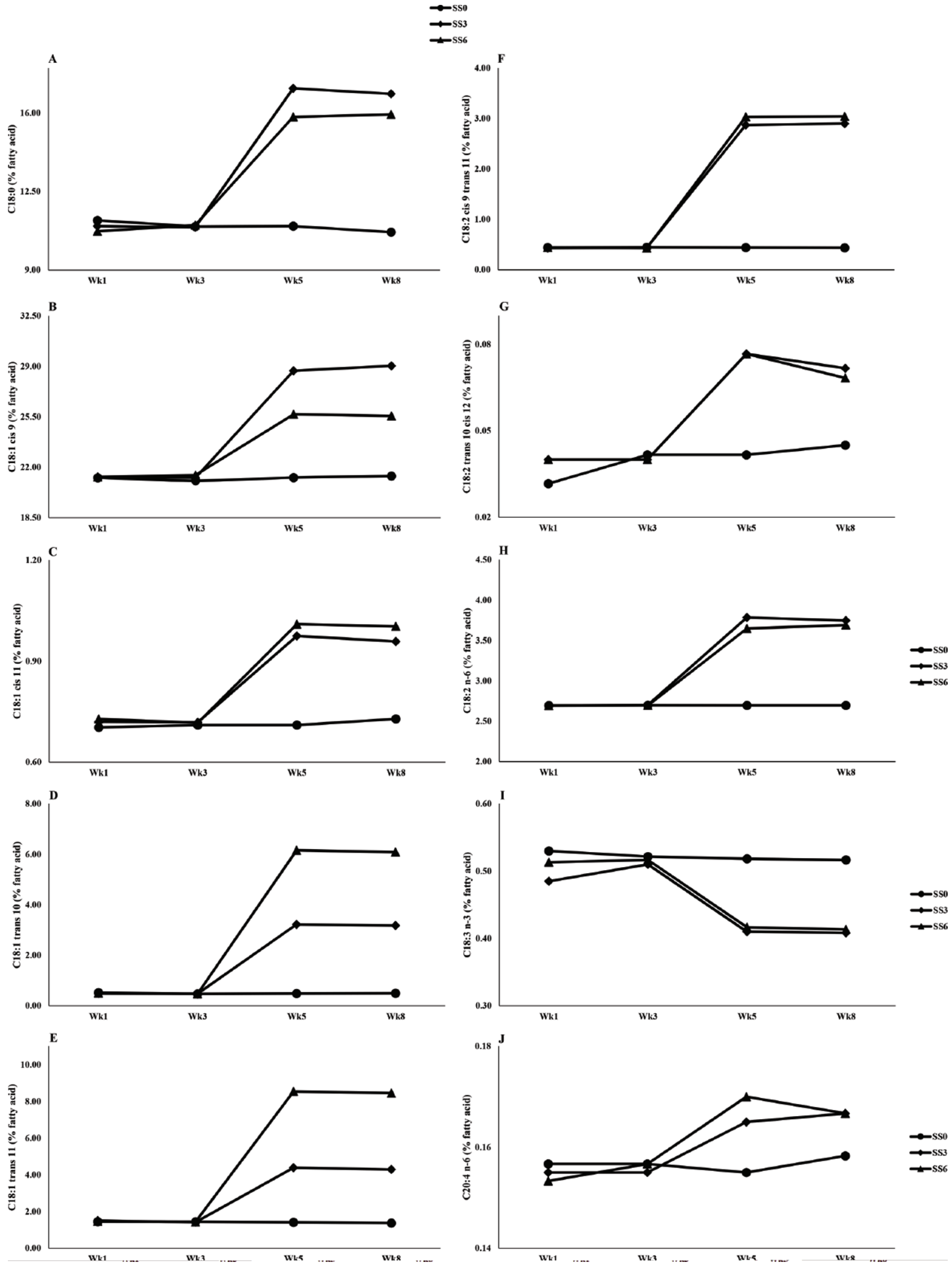

Figure 3. Changes in long-chain fatty acids with significant diet $\times$ week interactions (A, C18:0; B, C18:1 cis-9; C, C18:1 cis-11; D, C18:1 trans-11; E, C18:2 cis-9 trans-11; F, C18:2 trans-10 cis-12; G, C18:2 n-6; H, C18:3 n-3; I, C20:4 n-6) \% of total fatty acids expressed as methyl esters in milk of cows fed 3 levels of rolled safflower seed. SS0, SS3, SS6: dietary treatments of 0, 3, and 6\% rolled whole safflower seeds, respectively. Analyses were conducted separately for each week. The SE ranged from 0.21 to $7.20 \%$. 
Reported changes in milk FA due to feeding SS oil or seeds are confounded. Bell et al. (2006) fed diets with $6 \%$ of diet DM safflower oil and obtained changes in milk FA composition similar to those noted in our study. In comparison to Bell et al. (2006), the cows fed SS6 in our study would be consuming $2.4 \% \mathrm{DM}$ as safflower oil. The level of safflower oil used by Bell et al. (2006) resulted in lower MFPct without affecting DMI or MY. Wu et al. (1994) fed SS oil at $2.2 \%$ of DM, a level close to the present study, and also found milk FA changes similar to those of our study and observed
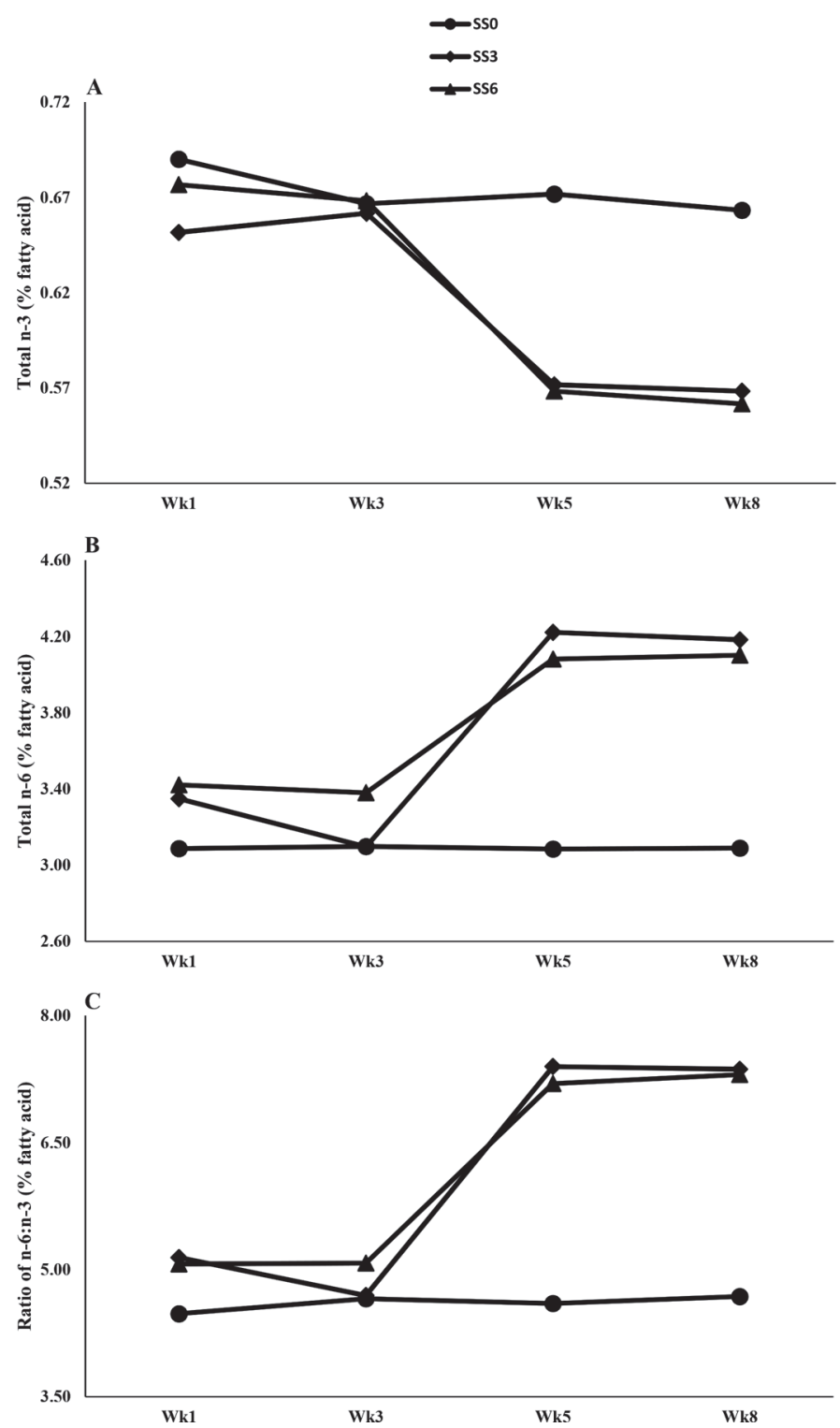

Figure 4. Diet $\times$ week interaction for n-3 (A), n-6 (B), and n-6:n-3 ratio (C) in milk of cows fed 3 levels of rolled safflower seed. SS0, SS3, SS6: dietary treatments of 0,3 , and $6 \%$ rolled whole safflower seeds, respectively. Analyses were conducted separately for each week. The SE ranged from 1.41 to $6.46 \%$. no changes in MFPct. When Alizadeh et al. (2012) fed a diet with $2.5 \%$ roasted, ground SS, the milk FA profile changed only in that C8:0 was decreased as was C16:0, but other FA were not changed. In their study, DMI, MY, and MFY were increased, and MFPct was numerically, but not statistically, increased by feeding SS. On the other hand, Stegeman et al. (1992) fed 10\% whole raw SS and observed similar changes in milk FA as in this study; however, DMI and MFPct were decreased whereas MY was increased. More recent work (Dschaak et al., 2010), in which diets ranging from 1 to $4 \%$ whole raw SS were fed, found that when SS was $1 \%$ of the diet, the $\%$ of SCFA and MCFA in milk FA were increased, whereas LCFA were decreased with CLA increased at the expense of C18:1. In that study (Dschaak et al., 2010), the concentrations of SCFA and MCFA in milk were decreased as SS in the diet increased such that when $3 \%$ SS was fed, milk SCFA and MCFA were decreased and LCFA, including CLA, were increased. Interestingly, MY was not affected, although the $1 \%$ level of SS in the diet decreased DMI, whereas the other levels had no effect. The MFY as well as the MFPct were increased by feeding $1 \%$ SS, but they were decreased as SS in the diet increased from 2 to $4 \%$ DM. This work strongly suggested that small SS additions to the diet had a stimulatory effect on MY and MFY. This level of SS was not evaluated in our study. In a further study feeding 3\% DM whole, raw SS of 2 cultivars differing in amount of EE, Dschaak et al. (2011) found changes in milk FA similar to those found in our study without changes in DMI or MY, but with significant decreases in MFPct and MFY. However, they followed FA changes for only $21 \mathrm{~d}$ compared with the $56 \mathrm{~d}$ of our study.

The wide range of both milk FA and production responses after feeding safflower oil or SS noted in the previously described studies as well as our own data suggest that differences must exist in the availability of the fat in SS. The exact reason for this is not clear, although availability of fat for rumen bio-hydrogenation may be a difference. Although in the present study the digestibility of total EE increased as the fat in the diet increased, large differences were present in the digestion of EE between the SS3 diet compared with SS6 (Figure $6 \mathrm{~A})$. Regression analysis indicated that digestion in the SS0 fed cows was linear across the weeks of the study, whereas cows fed SS3 displayed a concave curvilinear digestibility \% over the course of the study, and cows fed SS6 displayed a convex curvilinear digestibility (Figure $6 \mathrm{~B})$. Increasing amounts of vegetable fats were reported not to change EE digestion (Wu et al., 1994; Kalscheur et al., 1997). Godfrey (2007) determined that OM of SS was difficult to digest and suggested that grinding was the best method of increasing digestibility. However, 
the studies of Dschaak et al. (2010, 2011) indicated that fat in whole raw SS could be sufficiently digested, whereas fat in ground SS may not be (Alizadeh et al., 2012).

Abomasally infused CLA increased milk CLA within hours of infusion (Perfield et al., 2004; Harvatine and Bauman, 2011). Feeding oils in lower amounts than the equivalent oil in our study took days to initiate changes in milk FA (Roy et al., 2006; Shingfield et al., 2006). Interestingly, both studies found that trans FA in milk, including CLA, were increased until d 8 to 10 of feeding oils, but levels tended to return to pre-treatment levels by d 20 to 28. In their studies, MFY and MFPct, as well as SCFA and MCFA, declined throughout the studies. Bell et al. (2006) reported the time course of CLA changes when feeding safflower oil and found it took 2 wk to initiate FA changes. The CLA then maintained a plateau for the rest of the study. In our study, with the exception of C8:0, whose decline started in the first week, FA distribution in milk remained constant for 3 wk before initiating changes. Then, by wk 5 , most FA reached a plateau that did not change by the end of the study. The reason that C8:0 should show this pattern so much different than the other FA is not clear, as C6:0, C8:0, and C10:0 are apparently synthesized by the same process. Combined with the study by Bell et al. (2006), our study would appear to indicate that the well-reported effects of CLA on milk FA distribution

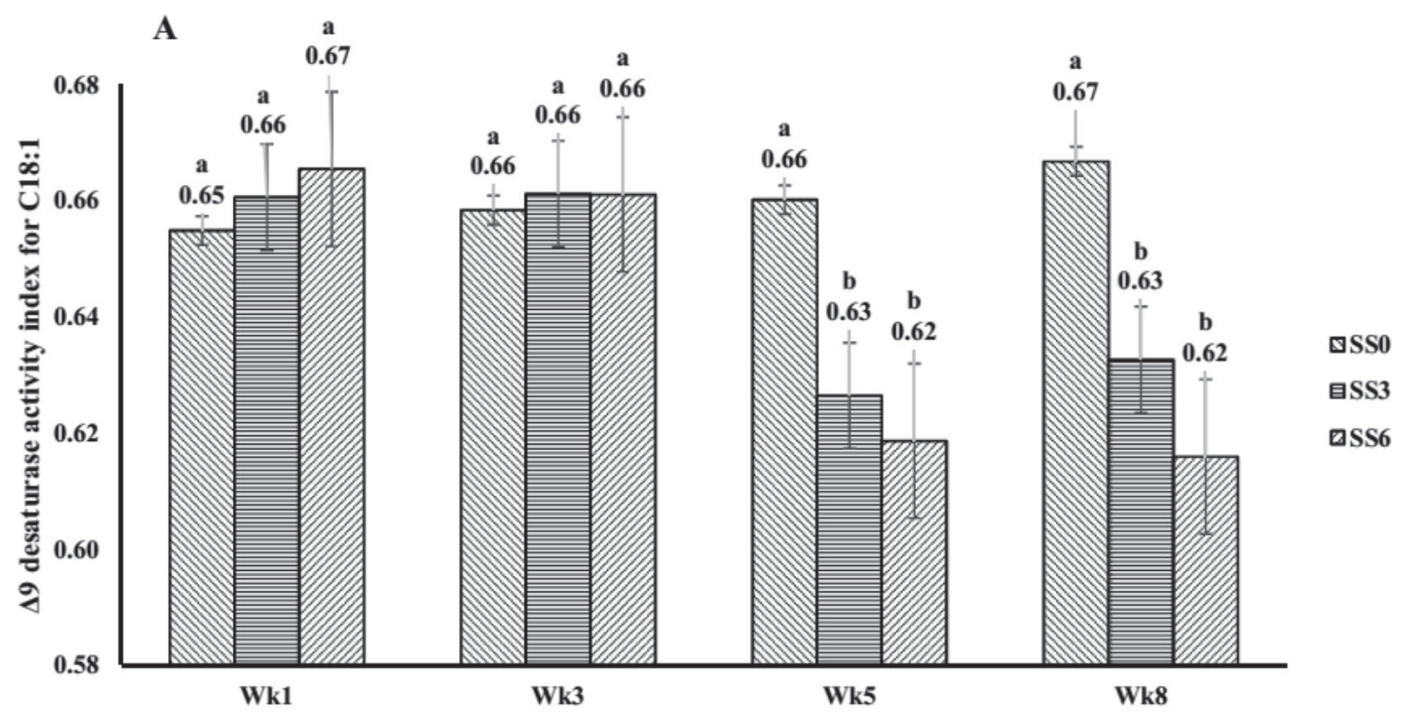

B

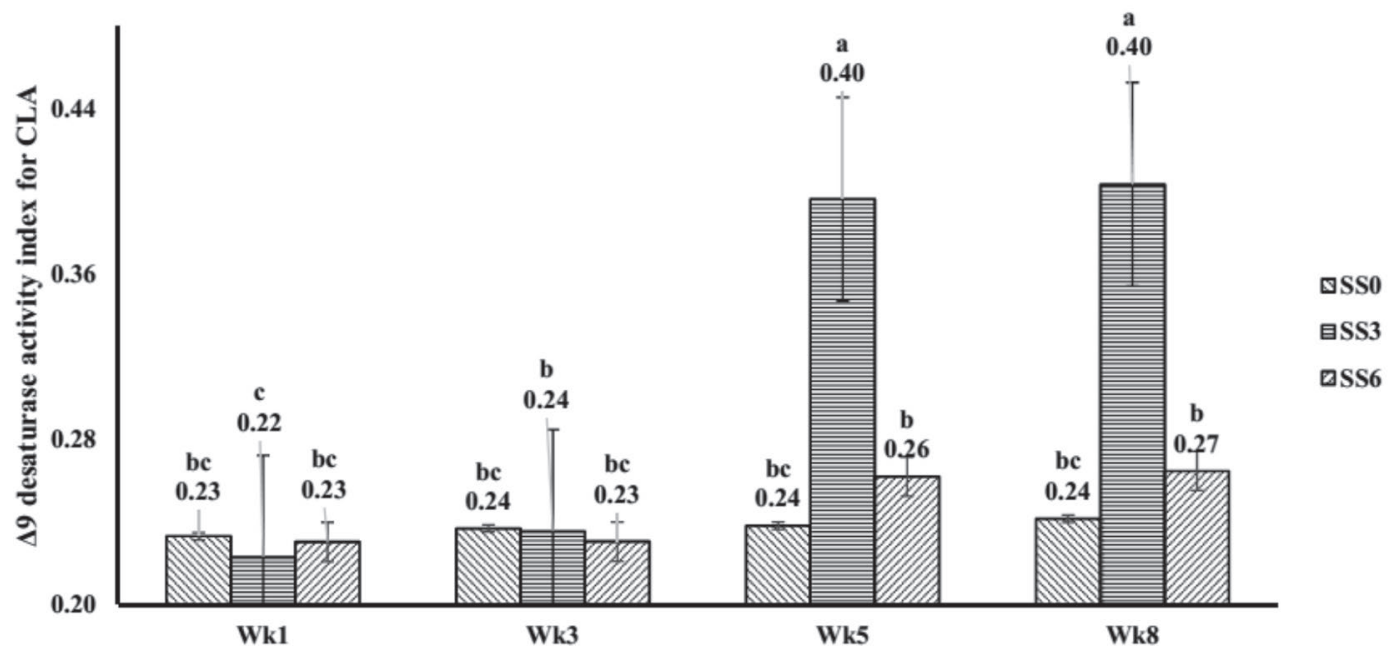

Figure 5. Diet $\times$ week interaction for the desaturation indexes for C18:1 (A) and CLA (B) affected by dietary treatments. SS0, SS3, SS6: dietary treatments of 0,3 , and $6 \%$ rolled whole safflower seeds, respectively. Means that do not have a common superscript differ at $P<0.05$. Error bars indicate the standard deviations. 

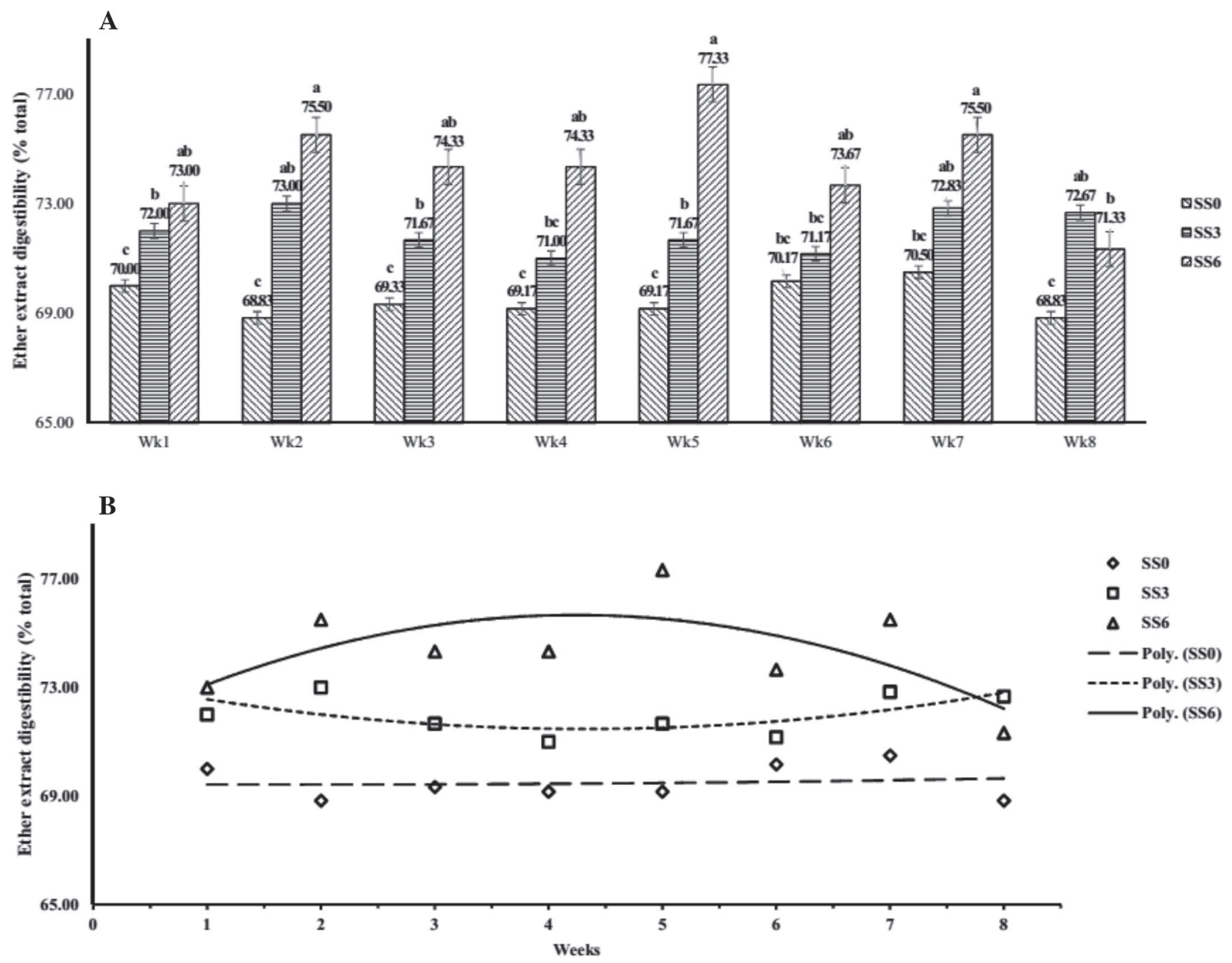

Figure 6. Ether extract digestibility (A) in cows fed 3 levels of rolled safflower seed over the 8 wk of the experiment and best fit regression equations of ether extract digestibility (B). SS0, SS3, SS6: dietary treatments of 0,3 , and $6 \%$ rolled whole safflower seeds, respectively. Means that do not have a common superscript differ at $P<0.05$. Digestibility of SS0 $=69.446+\left(0.0059 \times\right.$ wk $\left.^{2}\right)-(0.0218 \times$ wk $) ; \mathrm{R}^{2}=0.02 ;$ digestibility of SS3 $=73.327+\left(0.0992 \times \mathrm{wk}^{2}\right)-(0.8571 \times \mathrm{wk}), \mathrm{R}^{2}=0.42$; digestibility of SS6 $=71.286+(2.0694 \times \mathrm{wk})-\left(0.244 \times \mathrm{wk}{ }^{2}\right), \mathrm{R}^{2}=0.47$. Poly is the polygonal trend line for means in the trial period. Error bars indicate the standard deviations.

are reduced in animals fed SS, at least in comparison to other sources of UFA at similar levels of SS oil intake. A reason for this may be found in the DSI CLA data. It appears that the desaturase was downregulated by higher amounts of SS oil, which limited the rate and amount of CLA produced so that it does not reach the critical level where MFY and MFPct are reduced, but still allowed higher levels of CLA than in the control rations. It is the $\Delta^{9}$-desaturase in the body of the cow, and not flow of CLA from the rumen, that is the major source of CLA in milk (Dhiman et al., 2000). However, because the individual cow is the largest source of variation for CLA production (Kelsey et al., 2003), cow variation cannot be ruled out as the source of the DSI CLA as well as the possible influence of variable digestibility discussed above. Based on the SE data of this study and the SE of Kelsey et al. (2003), and using the method outlined by Gill (1978), in future studies it would take 20 cows per treatment to have an $80 \%$ chance of detecting a difference of 0.01 in the DSI C18:2 at $\alpha=0.05$.

The other noticeable feature of this study was that the decline for SCFA and MCFA and the increase for LCFA reached and maintained a plateau, whereas for other studies the levels of LCFA returned toward normal after hitting either their nadir or peak within a 
period of days. This maintenance of milk FA profile would seem to be a characteristic of SS oil, although other studies are needed to confirm this. The one drawback to the use of SS would be the increase in n- 6 FA. This may signify a pro-inflammatory status for the cow (Greco et al., 2015) with adverse health consequences, as well as risk for consumers of the milk as n-6 FA may also increase risk of cardiac disease in humans (Harris and von Schacky, 2004).

\section{CONCLUSIONS}

The present study indicates that SS can be fed to cows to increase CLA amounts in milk without greatly depressing milk fat production, although it would require 3 wk of feeding before an increase occurs. Additionally, the amount of CLA formation may be selflimiting. However, the CLA response occurs at the risk of producing a more pro-inflammatory $\mathrm{FA}$ balance in milk fat. Further studies will be required to establish proper feeding rates and optimum processing methods for SS.

\section{ACKNOWLEDGMENTS}

This study was financially supported by Bu-Ali Sina University (Hamedan, Iran). We thank Valliallah Shojaei and Marzban Brothers (Dairy Facility, Shahid Motahhari Agri-school, Ab-Barik, Iran) for their support in the farm work. The authors are grateful to Sima Mehri Kolchaki and Rachael G. Christensen from Utah State University for their useful suggestions.

\section{REFERENCES}

Alizadeh, A. R., M. Alikhani, G. R. Ghorbani, H. R. Rahmani, and J. J. Loor. 2012. Effects of feeding roasted safflower seeds (variety IL-111) and fish oil on dry matter intake, performance and milk fatty acid profiles in dairy cattle. J. Anim. Physiol. Anim. Nutr. (Berl.) 96:466-473.

AOAC International. 2002. Official Methods of Analysis. 16th ed. AOAC Int., Arlington, VA.

Bauman, D. E., and J. M. Griinari. 2001. Regulation and nutritional manipulation of milk fat: Low fat milk syndrome. Livest. Prod. Sci. 70:15-29.

Bell, J. A., J. M. Griinari, and J. J. Kennelly. 2006. Effect of safflower oil, flaxseed oil, monensin, and vitamin $\mathrm{E}$ on concentration of conjugated linoleic acid in bovine milk fat. J. Dairy Sci. 89:733-748.

Broderick, G. A., and J. H. Kang. 1980. Automated simultaneous determination of ammonia and total amino acids in ruminal fluid and in vitro media. J. Dairy Sci. 63:64-75.

Bu, D. P., J. Q. Wang, T. R. Dhiman, and J. J. Liu. 2007. Effectiveness of oils rich in linoleic and linolenic acids to enhance conjugated linoleic acid in milk from dairy cows. J. Dairy Sci. 90:998-1007.

Calder, P. C. 2012. Long-chain fatty acids and inflammation. Proc. Nutr. Soc. 71:284-289.

Chouinard, P. Y., L. Corneau, D. M. Barbano, L. E. Metzger, and D. E. Bauman. 1999. Conjugated linoleic acids alter milk fatty acid composition and inhibit milk fat secretion in dairy cows. J. Nutr. 129:1579-1584.
Dhiman, T. R., L. D. Satter, M. W. Pariza, M. P. Galli, K. Albright, and M. X. Tolosa. 2000. Conjugated linoleic acid (CLA) content of milk from cows offered diets rich in linoleic and linolenic acid. J. Dairy Sci. 83:1016-1027.

Dschaak, C. M., J.-S. Eun, A. J. Young, and J. W. Bergman. 2010. Nutritive merits of whole Nutrasaff safflower seed when fed to Holstein dairy cows during midlactation. Anim. Feed Sci. Technol. 156:26-36.

Dschaak, C. M., C. T. Noviandi, J.-S. Eun, V. Fellner, A. J. Young, D R. ZoBell, and C. E. Israelsen. 2011. Ruminal fermentation, milk fatty acid profiles and productive performance of Holstein dairy cows fed 2 different safflower seeds. J. Dairy Sci. 94:5138-5150.

Dubois, V., S. Breton, M. Linder, J. Fanni, and M. Parmentier. 2007. Fatty acid profiles of 80 vegetable oils with regard to their nutritional potential. Eur. J. Lipid Sci. Technol. 109:710-732.

Folch, J., M. Lees, and G. H. Sloane-Stanley. 1957. A simple method for the isolation and purification of total lipids from animal tissues. J. Biol. Chem. 226:497-509.

Gill, J. L. 1978. Design and Analysis of Experiments in the Animal and Medical Sciences Vol. 3. Iowa State University Press, Ames.

Glasser, F., M. Doreau, A. Ferlay, and Y. Chilliard. 2007. Technical Note: Estimation of milk fatty acid yield from milk fat data. J. Dairy Sci. 90:2302-2304.

Godfrey, L. R. 2007. Influence of method of processing and feeding level of safflower seeds on the performance of dairy cows. MS thesis. Animal, Dairy, and Veterinary Sciences Department, Utah State University, Logan.

Greco, L. F., J. T. Neves Neto, A. Pedrico, R. A. Ferrazza, F. S. Lima, R. S. Bisinotto, N. Martinez, M. Garcia, E. S. Ribeiro, G. C. Gomes, J. H. Shin, M. A. Ballou, W. W. Thatcher, C. R. Staples, and J. E. P. Santos. 2015. Effects of altering the ratio of dietary n- 6 to n-3 fatty acids on performance and inflammatory responses to a lipopolysaccharide challenge in lactating Holstein cows. J. Dairy Sci. 98:602-617.

Harris, W. S., and C. von Schacky. 2004. The omega-3 index: A new risk factor for death from coronary heart disease? Prev. Med. $39: 212-220$.

Harvatine, K. J., and D. E. Bauman. 2011. Characterization of the acute lactational response to trans-10, cis-12 conjugated linoleic acid. J. Dairy Sci. 94:6047-6056.

Huang, Y., J. P. Schoonmaker, B. J. Bradford, and D. C. Beitz. 2008. Response of milk fatty acid composition to dietary supplementation of soy oil, conjugated linoleic acid or both. J. Dairy Sci. 91:260-270.

Hurley, W. L., G. J. Warner, and R. R. Grummer. 1987. Changes in triglyceride fatty acid composition of mammary secretions during involution. J. Dairy Sci. 70:2406-2410.

Kalscheur, K. F., B. B. Teter, L. S. Piperova, and R. A. Erdman. 1997. Effect of fat source on duodenal flow of trans-C18:1 fatty acids on milk fat production in dairy cows. J. Dairy Sci. 80:2115-2126.

Kelsey, J. A., B. A. Corl, R. J. Collier, and D. E. Bauman. 2003 The effect of breed, parity and stage of lactation on conjugated linoleic acid (CLA) in milk fat from dairy cows. J. Dairy Sci. 86:2588-2597.

Lock, A. L., and D. E. Bauman. 2004. Modifying milk fat composition of dairy cows to enhance fatty acids beneficial to human health. Lipids 39:1197-1206.

NRC. 2001. Nutrient Requirements of Dairy Cattle. 7th rev. ed. Natl. Acad. Press, Washington, DC.

Parodi, P. W. 1999. Linoleic acid and other anticarcinogenic agents of bovine milk fat. J. Dairy Sci. 82:1339-1349.

Perfield, J. W. II, A. Sæbø, and D. E. Bauman. 2004. Use of conjugated linoleic acid (CLA) enrichments to examine the effects of trans-10 CLA, and cis-11, trans-13 CLA on milk-fat synthesis. J. Dairy Sci. 87:1196-1202

Rico, D. E., Y. Ying, and K. J. Harvatine. 2014. Effect of a high palmitic acid fat supplement on milk production and apparent total-tract digestibility in high- and low-milk yield dairy cows. J. Dairy Sci. 97:3739-3751.

Roy, A., A. Ferlay, K. J. Shingfield, and Y. Chilliard. 2006. Examination of the persistency of milk fatty acid composition in responses 
to plant oils in cows given different basal diets, with particular emphasis on trans-C18:1 fatty acids and isomers of conjugated linoleic acid. Anim. Sci. 82:479-492.

Shingfield, K. J., C. K. Reynolds, G. Hervas, J. M. Griinari, A. S. Grandison, and D. E. Beever. 2006. Examination of the persistency of milk fatty acid composition responses to fish oil and sunflower oil in the diet of dairy cows. J. Dairy Sci. 89:714-732.

Stegeman, G. A., D. P. Casper, D. J. Schingoethe, and R. J. Baer. 1992. Lactational responses of dairy cows fed unsaturated dietary fat and receiving bovine somatotropin. J. Dairy Sci. 75:1936-1945.

Tajik, J., M. G. Nadalin, A. Raoofi, G. G. Mohammadi, and A. R. Bahonar. 2011. Evaluation of rumenocentesis practicability as a routine diagnostic technique in veterinary practice. Vet. Arh. 81:557-561.

Van Keulen, J., and B. A. Young. 1977. Evaluation of acid-insoluble ash as a natural marker in ruminant digestibility studies. J. Anim. Sci. 44:282-287.
Van Soest, P. J., J. B. Robertson, and B. A. Lewis. 1991. Methods for dietary fiber, neutral detergent and nonstarch polysaccharides in relation to animal nutrition. J. Dairy Sci. 74:3583-3597.

van Valenberg, H. J. F., K. A. Hettinga, J. Dijkstra, H. Bovenhuis, and E. J. M. Feskens. 2013. Concentration of n-3 and n-6 fatty acids in Dutch bovine milk fat and their contribution to human dietary intake. J. Dairy Sci. 96:4173-4181.

Wu, Z., J. T. Huber, S. C. Chan, J. M. Simas, K. H. Chen, J. G. Varela, F. Santos, C. Fontes Jr., and P. Yu. 1994. Effect of source and amount of supplemental fat on lactation and digestion in cows. J. Dairy Sci. 77:1644-1651.

Zhong, R. Z., J. G. Li, Y. X. Gao, Z. L. Tan, and G. P. Ren. 2008. Effects of substitution of different levels of steam-flaked corn for finely ground corn on lactation and digestion in early lactation dairy cows. J. Dairy Sci. 91:3931-3937. 